\title{
Mathematical Modeling of the Propagation of Democratic Support of Extreme Ideologies in Spain: Causes, Effects, and Recommendations for Its Stop
}

\author{
E. De la Poza, ${ }^{1}$ L. Jódar, ${ }^{2}$ and A. Pricop ${ }^{2}$ \\ ${ }^{1}$ Departmento de Economía y Ciencias Sociales, Universitat Politècnica de València, 46022 Valencia, Spain \\ ${ }^{2}$ Instituto Universitario de Matemática Multidisciplinar, Universitat Politècnica de València, 46022 Valencia, Spain \\ Correspondence should be addressed to E. De la Poza; elpopla@esp.upv.es
}

Received 3 August 2013; Accepted 23 September 2013

Academic Editor: Francisco Solís Lozano

Copyright (C) 2013 E. De la Poza et al. This is an open access article distributed under the Creative Commons Attribution License, which permits unrestricted use, distribution, and reproduction in any medium, provided the original work is properly cited.

\begin{abstract}
This paper deals with the construction of a discrete population mathematical model for the short-term forecast until January 2016 of the electoral support of extreme ideology parties in Spain. Firstly, the nontrivial concept of extreme ideology is stated. Then, the electoral register is split in three subpopulations: supporters of extremist parties, abstentions/blank voters, and supporters of establishment parties. The model takes into account the following variables: economy measured throughout the Spanish unemployment rate; demography quantified in terms of birth and death rates and emigration; sociopolitical situation measured by the Spanish poverty indicator, trust on the Government labor indicator (GLI), and the indicator of political trust. By considering the dynamic subpopulations transits built throughout data obtained from public and private prestigious institutions and sociopolitical analysis, a system of difference equations models the electoral population behavior in Spain allowing us to compute the expected electoral support in the time horizon of January 2016. Sensitivity analysis versus uncertain parameters is performed in order to improve the reliability of the model results.
\end{abstract}

\section{Introduction}

It is difficult to believe that Europe could perform its economic recovery if previously it does not achieve confidence in its political system. The depth and length of the European economic crisis with high levels of unemployment (mainly youth), public debt, increasing taxation, and welfare deterioration combined with a lack of solutions by Government parties as well as the so called "cartelization" of the political parties are producing the emergence of political offers breaking the limits of traditional European trends. Thus, the populist and extremist political offers are not infrequent at the present times [1], and the Government parties are losing their power by each election period since 2008 .

Literature is abundant in studies focused on the use of surveys or previous election's results applying purely statistic analysis and techniques [2]. However, these approaches are not reliable in the current situation previously described due to the radical changes produced in the behavior of the European citizens and governments by the hard economic crisis.

In this paper, we propose a population discrete mathematical model represented by a system of difference equations to forecast in the short-term horizon of 2015 the electoral support of establishment and extremist parties as well as the level of abstention and blank voters. In fact the present situation in Spain is very special due to the combination of the economic and institutional crisis [3-6].

The study of the propagation of the extremist vote may be useful to recommend measures to prevent the risk of political instability by the implementation of political and economical alternatives focused on curbing the electoral propagation of extreme ideologies.

For the sake of accuracy and reliability, the period of study is split into quarters of year. Our approach splits the Spanish register of voters into three subpopulations. 
The aim of this paper is the construction of a mathematical model for short-term (next national elections) forecast of the electoral support of Spanish citizenship up to 2015. Individual behavior may be erratic, but aggregate behavior is often quite predictable [7]. Our approach is epidemiological dealing with populations instead of individuals. The foundations of such approach are based on the mimetic human behavior [8], human herding [9], and social contagion [10].

The register of voters is split into three categories or subpopulations. The three relevant subpopulations are explained below.

(1) The extremist voters (EX) are identified as followers of any of these three alternatives.

(i) Breakers of the constitutional order (separatists).

(ii) Breakers of the capitalist system.

(iii) Those who are disrespectful of the human rights (racists of gender, race, minorities...).

(2) The second subpopulation is called abstentions (AB) composed of those potential electors who do not vote or plan to vote [11].

(3) In addition, the establishment voters (ES) composed of those citizens planning of vote for a nonextremist party that also achieved representation on the Spanish parliament for at least the last three national elections.

It is important to point out that these definitions depend on the type of election we are managing. In fact, nowadays there are political parties in Spain like Convergència i Unió $(\mathrm{CiU})$ that play the role of extremists $(\mathrm{EX})$ in the national elections, while in the Autonomous Community elections $\mathrm{CiU}$ and others they play the role of establishment parties (ES). This occurs because of the recent strategy of separatism developed by $\mathrm{CiU}$. However, in this study we only focus on national elections.

It is worthy to remark that unlike what happens in Spain, in many European countries the extremist parties are represented by racist ideology parties [1].

It is important to point out that we use electoral data coming from the last three Spanish general elections (2004, 2008, and 2011) in order to know the initial level of each subpopulation. Then, we will study the dynamic subpopulations' transits taking into account economic (Spanish unemployment rate), demographic (birth rate, death rate, and emigration), and socio-political (corruption indicator, poverty index, and the trust Government's labor indicator) factors. Thus, solving the difference equation system, the amount of supporters of each subpopulation is quantified.

This type of population approach has been recently employed in the study of sociological problems such as anxiolytic consumption dependency [12], workaholism [13], and compulsive shopping behavior [14].

The paper is organized as follows. Section 2 deals with mathematical model construction with an explicit computation of the subpopulations coefficients transits. Results and simulations are included in Section 3. Section 4 shows the robustness of the model throughout changes in the Government labor indicator (GLI) and also the political trust indicator. Finally, conclusions and recommendations section is included.

\section{Model Construction}

This section embraces the description of the population of study, then the sources of information and hypotheses employed and the modeling of the dynamic subpopulations transits.

The target population is composed of the Spanish citizens older than 18 years old. The total amount of the population is affected by demographic factors such as emigration, immigration, and birth and death rates.

We are building a discrete dynamic epidemiological model whose subpopulations are quarterly estimated. This way, we start forecasting the citizenship vote intention in Spanish national elections. Our period of study starts in January 2012 and ends at January 2016, splitted it into quarters.

Our starting hypothesis is that subpopulations change dynamically and these variations depend mainly of demographic factors (emigration, birth and death rates), economic ones (unemployment rate, poverty indicator), and sociological trends (Government and political trust indicators). The transit between subpopulations (ES, AB, and EX) is modeled by dynamic coefficients built on data provided by direct sources of information such as the Spanish Institute of Statistics (INE) [15], Center of Sociological Research (CIS) [16], the Organization for Economic Cooperation and Development (OECD) [17], Societé Générale Bank (SGB) [18], and International Monetary Fund (IMF) [19] combined with our hypotheses and analysis.

The financial and economic crisis started at the end of 2007 resulted in social and demographic changes. Due to the breakdown of the economic trend, we only take into account the national data of 2004, 2008 and 2011, since previous data does not provide evidence of this trend change.

The Spanish economic framework is characterized by high level of stable unemployment rates (above 20\%). Although we should distinguish between ideologized and non ideologized voters, in the present economic recession we assume that nonideologized ES voters transit to $A B$ after becoming unemployed. This means that if the unemployment increases in $1 \%$ then $0.01 \mathrm{ES}(n)$ people will transit to the subpopulation $\mathrm{AB}(n)$. By the same reason if the unemployment decreases in $1 \%$, then $0.01 \mathrm{AB}(n)$ would transit to $\operatorname{ES}(n)$. Thus, we are dealing with a type of citizens whose vote support is mainly dependent on the economy measured in terms of unemployment.

This approach is conservative in the sense that the new unemployed people could impact the electoral behavioral of his/her close neighborhood, for instance the family.

Thus, the transit between subpopulations $\operatorname{ES}(n)$ and $\mathrm{AB}(n)$ follows the rule:

$$
\alpha_{1}(n)=\left\{\begin{array}{cl}
0.01(\gamma(n)-\gamma(n-1)), & \gamma(n) \neq \gamma(n-1) \\
0.01, & \gamma(n)=\gamma(n-1)
\end{array}\right\},
$$




$$
\begin{array}{r}
\alpha_{1}(n)=\text { unemployment economic transit } \\
\text { effect between quarters } n \text { and } n+1, \\
\gamma(n)=\text { unemployment rate at quarter } n(\%) .
\end{array}
$$

A proportion of ideologized voters who used to vote for the establishment parties in the recent past change their vote due to their lack of political trust due to the continuous emergence of corruption cases combined with the increase of taxes and the deterioration of the welfare system. The Spanish political trust indicator performed quarterly by [16] calibrates this lack of political trust. These voters punish the ES parties by moving from $\operatorname{ES}(n)$ to $\operatorname{EX}(n+1)$ at $n+1$ quarter. Thus, we have the transit coefficient:

$$
\alpha 2(n)=C(\beta(n)-\beta(n-1)),
$$

where $\beta(n)$ is the value of the political trust indicator at quarter $n$.

The approximation of this proportion $C$ that is regarded as a sociological constant is adjusted by matching the electoral data of the last three Spanish general elections. After matching the data it turns out that $C=0.00299$.

As we commented previously, Spanish population is suffering from the consequences of long-term unemployment rate. A proportion of long-term unemployed citizens orient their vote intention towards extremist parties looking for possible solutions outside the ES parties. The non-ideologized citizen is affected by the principle of the continuity of transit which means moving from $\mathrm{AB}$ to $\mathrm{EX}$ instead of from ES to EX.

The proportion of population transiting from $\mathrm{AB}$ to $\mathrm{EX}$ is measured throughout the Spanish poverty indicator [20]. Analyzing the behavior of this indicator for the last 4 years (2008-2011) and assuming that this remains stable until 2015 (because the Spanish economy is not going to improve in an important degree), we found that this quarter rate is about $0.5 \%$ of the $\mathrm{AB}$ subpopulation.

Thus, the rate of radicalization due to Spanish poverty indicator is denoted by $\alpha_{3}(n)=\alpha_{3}$.

Finally, we consider the supporters of the Government parties to become disappointed with the labor of the Government changing their vote intention from ES to $\mathrm{AB}$. This may occurs due to two main reasons: the lack of Government's commitment with the electoral program and the weakness of Government's reaction to corruption scandals [21-23].

The coefficient $\alpha_{4}$ is expressed as follows:

$$
\begin{aligned}
& \alpha_{4}=0.329(f(n-1)-f(n)), \\
& f(n)=\text { is defined as the Government's } \\
& \text { labor indicator at quarter } n .
\end{aligned}
$$

This indicator is estimated quarterly by [16].

The constant factor 0.329 (32.9\%) means the proportion of susceptible ES voters that can move to other subpopulations due to the lack of confidence in Government. That is, about $67.1 \%$ of ES voters remain loyal to the previous ES voting intention. This percentage includes a proportion of the retired people among the age interval of (60-75) who are afraid of losing their pensions, also a proportion of public servants, clergy, military, the socialist labor union (UGT members), and ES political parties' members.

This factor 0.329 has been adjusted by using electoral data from the general elections of 2004, 2008, and 2011. The sociological factor 0.329 is assumed constant in the short period of study (January 2016) reflecting the level of loyalty from different population segments to the ES parties. The data of $f(n)$ are provided by [16] until July 2013. From this time until the end of our period of study (January 2016), we assume that $f(n)$ goes slightly down due to the continuous diffusion of corruption cases of the two main Spanish ES parties (PSOE and PP), also a persistent application of new taxes combined with the welfare system deterioration, and finally, the demographic factors composed of the birth and death rates and the new effect of Spanish emigrating abroad seeking for a job.

$\alpha_{b}(n-72)$ is the birth rate of the Spanish population at quarter $(n-72)$. This parameter is estimated according to the data coming from [15]. We assume that all Spanish citizens becoming 18-year-old entry into the system are distributed equally among the three subpopulations. Thus,

$$
\frac{B(n-72)}{3}=\frac{\alpha_{b}(n-72) P(n-72)}{3},
$$

where $B(n-72)$ is the number of births at quarter $(n-72)$ and $P(n-72)$ is the Spanish population at quarter $(n-72)$.

Then, the exit from the system could happen due to two reasons, the biological death measured throughout the death rate $\left(\alpha_{d}(n)\right)$ at quarter $n$, uniformly quarterly distributed. This parameter is estimated throughout data provided by [15]. We assume that this rate remains constant for the period from 2013 until 2015. Consider the following:

$$
\frac{D(n)}{3}=\alpha_{d}(n) \frac{P(n)}{3} \text {. }
$$

The second reason for exiting the model is the Spanish emigration effect due to the lack of jobs in the Spanish market. The Spanish emigration number is about 200,000 people per year. We assume that the amount of Spanish people leaving Spain $(E=150,000)$ remains constant due to the economic crisis until January 2016.

We assume that this exit amount occurs equally from ES and $\mathrm{AB}$ subpopulations, and even when they have the right to vote (remotely) we assume they do not.

In further section, we will study the robustness of the model under the change of values of indicator $f(n)$ for the period of 2013-2016.

The above analysis is mathematically written by the following equations and also illustrated in Figure 1:

$$
\begin{aligned}
\operatorname{ES}(n)= & \operatorname{ES}(n-1)-\alpha_{1}(n) \operatorname{ES}(n-1)-\alpha_{4}(n) \operatorname{ES}(n-1) \\
& -\alpha_{2}(n) \operatorname{ES}(n-1)+\frac{1}{3} B(n-72)-\frac{1}{3} D(n)-\frac{1}{2} E,
\end{aligned}
$$




$$
\begin{aligned}
\mathrm{AB}(n)= & \mathrm{AB}(n-1)+\alpha_{1}(n) \operatorname{ES}(n-1)+\alpha_{4}(n) \operatorname{ES}(n-1) \\
& -\alpha_{3} \mathrm{AB}(n-1)+\frac{1}{3} B(n-72)-\frac{1}{3} D(n)-\frac{1}{2} E \\
\operatorname{EX}(n)= & \operatorname{EX}(n-1)+\alpha_{2}(n) \operatorname{ES}(n-1)+\alpha_{3} \mathrm{AB}(n-1) \\
& +\frac{1}{3} B(n-72)-\frac{1}{3} D(n) .
\end{aligned}
$$

\section{Results and Simulations}

This section deals with quantification and simulation of the subpopulation sizes throughout the period of study.

As we mentioned above, we are considering the Spanish unemployment rate and the trust on the Government labor indicator. These indicators have relevance in the construction of the dynamic subpopulations' transits coefficients. It is clear that for the short-term future period (2013-2016), we should assume an estimation of these indicators.

Related to the economic one, there are some prestigious institutions forecasting these values. Thus, we built one pessimistic scenario based on [17] (for 2013, 2014) and on [18] for 2015, While the optimistic scenario is based on [19] forecast embracing the whole period. As our study is split into quarters of a year periods, we distribute uniformly by quarters the annual variation of the Spanish unemployment rate due to the annually of the available information (see Table 1).

On the other hand, the trust on the GLI is based on [16] for the periods of (2008 and 2013), but also at our own estimations for (2014 and 2016). We assume that due to the continuous publications of corruption events connected with the two main parties (PSOE and PP), this indicator evolves worsening until the end of the period of study (January 2016). The information about this indicator is provided quarterly (see Table 2).

Following, the values of the transits' coefficients of the model are expressed quarterly (see Table 3 ).

Computing the subpopulations $\mathrm{ES}(n), \mathrm{AB}(n)$, and $\operatorname{EX}(n)$, starting from the initial subpopulations at January 2012, using the difference system (6) one can estimate the values collected in Table 4.

We assume that the vote intention for January 2012 is the electoral results at November 2011.

As Table 4 shows and Figure 2 illustrates, at the end of the period of study, January 2016, the expected electoral support of ES parties achieves $47.71 \%$ in the pessimistic case, while in the optimistic one the ES electoral support amounts to $49.78 \%$. With respect to the extremist support (EX) it is $16.95 \%$ for the optimistic scenario and $17.62 \%$ for the pessimistic one. Finally with respect to the abstentions (AB) it is $33.27 \%$ in the optimistic scenario while $34.67 \%$ in the pessimistic one.

\section{Robustness of the Model}

As the main goal of the paper is the short-term forecast of the electoral support of the three involved subpopulations, it
TABLE 1: Spanish unemployment rate (\%).

\begin{tabular}{lcc}
\hline & Pessimistic & Optimistic \\
\hline 2011 & 21.7 & 21.7 \\
2012 & 25.0 & 25.0 \\
2013 & 27 & 27.0 \\
2014 & 28.1 & 26.0 \\
2015 & 30.0 & 24.7 \\
\hline
\end{tabular}

TABLE 2: Trust on the Spanish Government labor indicator (GLI), $\beta(n),(\%)$.

\begin{tabular}{lcc}
\hline & $\beta(n)$ Optimist & $\beta(n)$ Pessimist \\
\hline Oct-11 & 33.50 & 33.50 \\
Jan-12 & 42.70 & 42.70 \\
Apr-12 & 37.50 & 37.50 \\
Jul-12 & 32.90 & 32.90 \\
Oct-12 & 27.70 & 27.70 \\
Jan-13 & 29.30 & 26.25 \\
Apr-13 & 27.20 & 25.75 \\
Jul-13 & 26.55 & 25.25 \\
Oct-13 & 25.90 & 24.75 \\
Jan-14 & 25.25 & 24.25 \\
Apr-14 & 25.00 & 23.75 \\
Jul-14 & 24.75 & 23.25 \\
Oct-14 & 24.50 & 22.75 \\
Jan-15 & 24.25 & 22.25 \\
Apr-15 & 24.13 & 22.00 \\
Jul-15 & 24.00 & 21.75 \\
Oct-15 & 23.88 & 21.50 \\
Jan-16 & 23.75 & 21.25 \\
\hline
\end{tabular}

is necessary to assume the values of the trust on the GLI and the political trust indicator. Thus, it is convenient to analyze the sensitivity of the model results under changes in assumed values of these indicators.

4.1. Robustness of the Model versus the Trust on the Government Indicator. Due to the constant political cases of corruption affecting the two main parties, the trust on the Government indicator is assumed to decrease. However for the time horizon of our study we analyzed the sensitivity of our model under changes in this indicator values among the interval $[-0.5,0.25]$. As a result the subpopulations at year 2016 are estimated for the different values of the trust on the Government labor indicator (see Figure 3).

4.2. Robustness of the Model versus Political Trust Indicator. The coefficient that explains the transit from ES to EX due to the political trust is built by the expression $\alpha_{2}(n)=C(\beta(n)-$ $\beta(n-1))$, where $\beta(n)$ is the value of the political trust indicator at quarter $n$ and $C$ is a sociological constant that is adjusted taking into account the electoral data of the last three Spanish general elections.

In order to improve the reliability of the results of the model and as the estimations of this constant $C$ are 


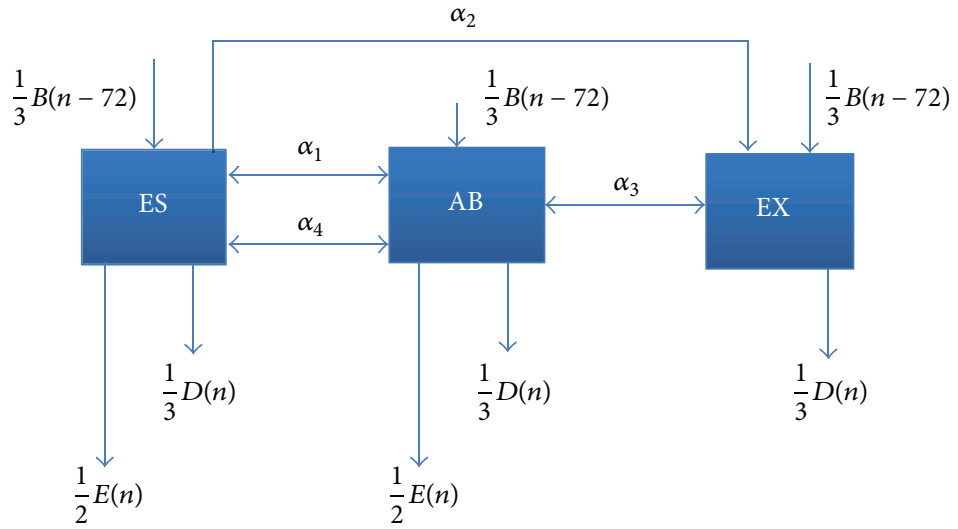

Figure 1: Block diagram system.

TABLE 3: Subpopulations' transits.

\begin{tabular}{|c|c|c|c|c|c|c|c|c|}
\hline \multirow{2}{*}{ Quarter } & \multicolumn{4}{|c|}{ Optimistic scenario } & \multicolumn{4}{|c|}{ Pessimistic scenario } \\
\hline & $\alpha_{1}(n)$ & $\alpha_{2}(n)$ & $\alpha_{3}$ & $\alpha_{4}(n)$ & $\alpha_{1}(n)$ & $\alpha_{2}(n)$ & $\alpha_{3}$ & $\alpha_{4}(n)$ \\
\hline Jan-12 & 0.008 & -0.02751 & 0.005 & -0.017931 & 0.008 & -0.02751 & 0.005 & -0.016 \\
\hline Apr-12 & 0.004 & 0.01555 & 0.005 & -0.017931 & 0.005 & 0.01555 & 0.005 & -0.016 \\
\hline Jul-12 & 0.004 & 0.01375 & 0.005 & 0.013489 & 0.005 & 0.01375 & 0.005 & 0.012 \\
\hline Oct-12 & 0.004 & 0.01555 & 0.005 & 0.02303 & 0.005 & 0.01555 & 0.005 & 0.02 \\
\hline Jan-13 & 0.004 & -0.00478 & 0.005 & -0.003619 & 0.005 & 0.00434 & 0.005 & -0.003 \\
\hline Apr-13 & -0.001 & 0.00628 & 0.005 & 0.005593 & 0 & 0.0015 & 0.005 & 0.005 \\
\hline Jul-13 & -0.001 & 0.00194 & 0.005 & 0.007896 & 0 & 0.0015 & 0.005 & 0.007 \\
\hline Oct-13 & -0.001 & 0.00194 & 0.005 & 0.001645 & 0 & 0.0015 & 0.005 & 0.001 \\
\hline Jan-14 & -0.002 & 0.00194 & 0.005 & 0.001645 & 0 & 0.0015 & 0.005 & 0.001 \\
\hline Apr-14 & -0.001 & 0.00075 & 0.005 & 0.001645 & -0.001 & 0.0015 & 0.005 & 0.001 \\
\hline Jul-14 & -0.001 & 0.00075 & 0.005 & 0.001645 & -0.001 & 0.0015 & 0.005 & 0.001 \\
\hline Oct-14 & -0.001 & 0.00075 & 0.005 & 0.001645 & -0.001 & 0.0015 & 0.005 & 0.001 \\
\hline Jan-15 & -0.001 & 0.00075 & 0.005 & 0.001645 & -0.001 & 0.0015 & 0.005 & 0.001 \\
\hline Apr-15 & -0.001 & 0.00037 & 0.005 & 0.001645 & 0.007 & 0.00075 & 0.005 & 0.001 \\
\hline Jul-15 & -0.001 & 0.00037 & 0.005 & 0.001645 & 0.007 & 0.00075 & 0.005 & 0.001 \\
\hline Oct-15 & -0.001 & 0.00037 & 0.005 & 0.001645 & 0.007 & 0.00075 & 0.005 & 0.001 \\
\hline Jan-16 & -0.002 & 0.00037 & 0.005 & 0.001645 & 0.007 & 0.00075 & 0.005 & 0.001 \\
\hline
\end{tabular}

approximated, it is convenient to study the sensitivity of the model results under changes in this parameter.

As a result $C$ was estimated in the value interval $[1 / 2 C, 3 / 2 C]$, what allow us to compute the subpopulations results at 2016 (see Figure 4).

\section{Conclusions and Recommendations}

From the mathematical point of view, the proposed model could be easily replicated to study the electoral behavior of any other country with the obvious considerations of appropriate electoral data, socio-political-economic indicators, electoral laws, [24-27] and demographic factors.

The model predicts that the support of abstentions and blank voters, that is, the subpopulation $\mathrm{AB}$, remains approximately constant since the last election in November 2011 until the expected time (if general elections are not held in advance) in spite of the coming reduction of the electoral register of about 800,000 Spanish citizens who emigrate looking for a job (we assume that they do not vote).

On the other hand, the predicted electoral support of the two main parties (PP and PSOE) scarcely will achieve $40 \%$ in the next general elections, while in the previous general elections they got a support of $49 \%$ of the register. This scenario includes an important increase of minor ES parties like UPyD, Ciutadants. This situation is combined with a highly important growth of support of extremist parties, moving from $11 \%$ to $17.5 \%$ that in absolute terms means to be an increase of more than 2 millions of supporters.

The previous results imply that probably it is not going to be possible to get sufficient electoral support to constitute a Government without extremist parties. It looks like the only possible imagined Government coalition would involve at least three parties, including between them one extremist 
TABLE 4: Forecasted subpopulations by quarters.

\begin{tabular}{|c|c|c|c|c|c|c|}
\hline \multirow{2}{*}{ Quarter } & \multicolumn{2}{|c|}{ ES } & \multicolumn{2}{|c|}{$\mathrm{AB}$} & \multicolumn{2}{|c|}{ EX } \\
\hline & Optimist & Pessimist & Optimist & Pessimist & Optimist & Pessimist \\
\hline Jan-12 & $19,238,081$ & $19,238,081$ & $11,764,115$ & $11,764,115$ & $3,975,684$ & $3,975,684$ \\
\hline Apr-2012 & $19,191,070$ & $19,191,070$ & $11,418,760$ & $11,418,760$ & $4,328,902$ & $4,328,902$ \\
\hline Jul-12 & $18,575,355$ & $18,575,355$ & $11,678,532$ & $11,678,532$ & $4,645,003$ & $4,645,003$ \\
\hline Oct-12 & $17,768,050$ & $17,768,050$ & $12,103,273$ & $12,103,273$ & $4,987,024$ & $4,987,024$ \\
\hline Jan 2013 & $17,805,227$ & $17,623,338$ & $12,005,133$ & $12,026,023$ & $4,956,742$ & $5,117,742$ \\
\hline Apr-13 & $17,595,761$ & $17,489,724$ & $11,993,195$ & $12,023,580$ & $5,122,528$ & $5,198,179$ \\
\hline Jul-13 & $17,423,610$ & $17,320,809$ & $12,020,360$ & $12,055,407$ & $5,210,029$ & $5,277,783$ \\
\hline Oct-13 & $17,361,189$ & $17,248,098$ & $11,936,752$ & $11,989,883$ & $5,296,712$ & $5,356,672$ \\
\hline Jan-14 & $17,298,280$ & $17,174,964$ & $11,852,936$ & $11,923,981$ & $5,382,237$ & $5,434,508$ \\
\hline Apr-14 & $17,248,253$ & $17,119,914$ & $11,778,890$ & $11,841,857$ & $5,447,243$ & $5,512,615$ \\
\hline Jul-14 & $17,199,008$ & $17,065,668$ & $11,705,893$ & $11,760,845$ & $5,512,554$ & $5,590,941$ \\
\hline Oct-14 & $17,150,543$ & $17,012,227$ & $11,633,942$ & $11,680,938$ & $5,578,174$ & $5,669,494$ \\
\hline Jan-15 & $17,102,858$ & $16,959,588$ & $11,563,031$ & $11,602,133$ & $5,644,111$ & $5,748,279$ \\
\hline Apr-15 & $17,069,824$ & $16,783,681$ & $11,483,534$ & $11,659,030$ & $5,702,907$ & $5,813,555$ \\
\hline Jul-15 & $17,036,449$ & $16,608,988$ & $11,404,072$ & $11,713,840$ & $5,760,934$ & $5,878,626$ \\
\hline Oct-15 & $17,002,733$ & $16,435,501$ & $11,373,139$ & $11,766,587$ & $5,769,698$ & $5,943,482$ \\
\hline Jan-16 & $16,968,678$ & $16,263,210$ & $11,341,868$ & $11,817,290$ & $5,778,069$ & $6,008,115$ \\
\hline
\end{tabular}

Op: Optimistic scenario; Pe: Pessimistic scenario.

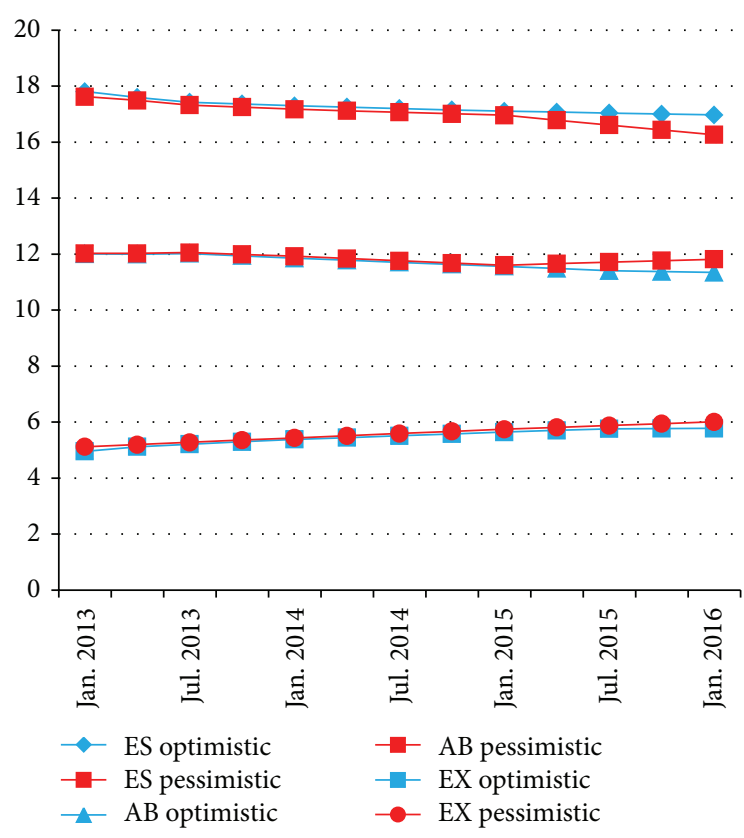

FIGURE 2: Trend of the subpopulations (expressed in millions).

party. In some way this paper advances the end of the hegemonic two-party system in Spain although is well known that the Spanish electoral system favors the two party-system $[24,26]$.

As results of the model show, the economic crisis favors the shift of a part of ES voters to abstentions $(A B)$ and from $\mathrm{AB}$ to EX. Thus, all types of measures addressed to improve the economic scenario of the country will help to stop this trend. In our opinion, which agrees with [5], unlike the

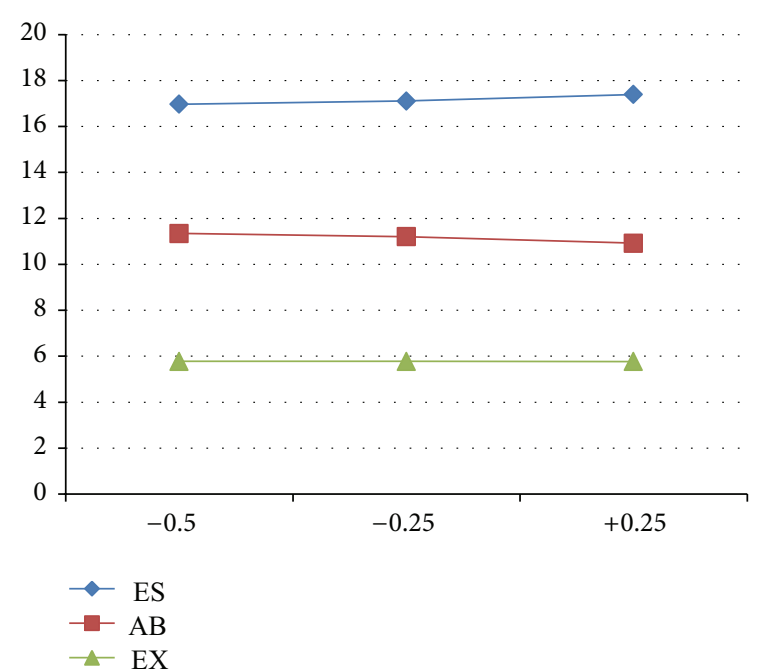

FIGURE 3: Sensitivity analysis of trust on the GLI (Millions of predicted voters).

current measures of the Government, they are focused on a growth of taxes and also an irrelevant reduction of the public spending.

We mean that the cuts of the public spending should not be only addressed to reduce the size of public servants staff but mainly consultants are directly chosen without any technical or professional filter by local, regional, and national politicians (about 1,500,000 people in 2011, [5]). The current Government is not aware that Spanish citizens are waiting for an important reduction of the public spending related to the job of political administrators instead of a continuous growth of taxes and cuts of the welfare system. 


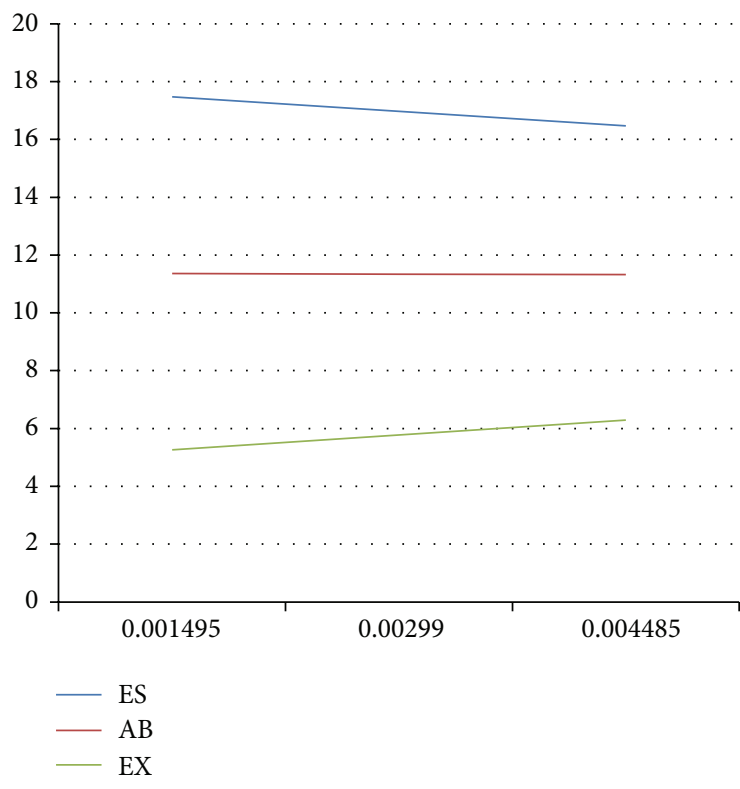

FIGURE 4: Sensitivity analysis of the political trust indicator (Millions of predicted voters).

Apart from these issues, the lack of compliance of the electoral programs has an influence on the shift of ES voters (supporting the Government) to the abstentions (AB), and also the ES voters may punish the Government by voting for extremist parties.

In order to reduce the progressive political and institutional disappointment of Spanish citizens, it is clear that measures preventing the political corruption, political privileges, and excesses as well as an improvement of the transparency of public activity are necessary and urgent. Just to quote some of them, we have a reform of the constitution, stabilizing the political territorial administration (against the separatist stresses), the elimination of the public financial support to labor unions and firm associations, new formulas of management for expensive public services. What is also urgent is a reform of the current political parties law to improve the transparency of the political system as well as a change of the electoral law that punishes the appearance of new emergent political offers $[4,6,28]$.

\section{Acknowledgments}

The authors of this paper would like to thank Phd. Pauwels from Universite Libre de Bruxelles and also Professor Eva Anduiza and her coworkers from Universidad Autónoma de Barcelona (UAB) for their valuable comments that have enriched our research. The authors would also thank the Universitat Politècnica de València since this paper has been financed through the Grant PAID06-11-2070.

\section{References}

[1] T. Pauwels, The populist voter [Ph.D. thesis], Université Libre de Bruxelles, 2012.
[2] J. Evans and G. Ivaldi, "Comparing forecast models of radical right voting in four European countries (1973-2008)," International Journal of Forecasting, vol. 26, no. 1, pp. 82-97, 2010.

[3] K. Rogoff and C. Reinhart, This Time Is Different, Princeton University Press, 2009.

[4] S. Muñoz-Machado, Informe Sobre España, E. Critica, Bacelona, Spain, 2012, (Spanish).

[5] J. R. Rallo, Una Alternativa Liberal Para Salir de la Crisis, Deusto, Barcelona, Spain, 2012, (Spanish).

[6] A. Vidal-Quadras, Ahora, Cambio de Rumbo, Planeta, Barcelona, Spain, 2012.

[7] C. R. MacCluer, Industrial Mathematics: Modeling in Industry, Science, and Government, Prentice Hall, Upper Saddle River, NJ, USA, 2000.

[8] R. Girard, Mimesis and Theory: Essays on Literature and Criticism, 1953-2005, Stanford University Press, 2008.

[9] R. M. Raafat, N. Chater, and C. Frith, "Herding in humans," Trends in Cognitive Sciences, vol. 13, no. 10, pp. 420-428, 2009.

[10] N. A. Christakis and J. H. Fowler, Connected: the Surprising Power of Our Social Networks and How they Shape Our Lives, Back Bay Books, Little Brown and Company, 2009.

[11] E. Anduiza and A. Bosch, Comportamiento Político Y Electoral, Ariel, Barcelona, Spain, 2012, (Spanish).

[12] E. de la Poza, N. Guadalajara, L. Jódar, and P. Merello, "Modeling Spanish anxiolytic consumption: economic, demographic and behavioral influences," Mathematical and Computer Modelling, vol. 57, no. 7-8, pp. 1619-1624, 2013.

[13] E. de la Poza, M. del Líbano, I. García, L. Jódar, and P. Merello, "Predicting workaholism in Spain: a discrete mathematical model," International Journal of Computer Mathematics, 2013.

[14] I. García, L. Jódar, P. Merello, and F.-J. Santonja, "A discrete mathematical model for addictive buying: predicting the affected population evolution," Mathematical and Computer Modelling, vol. 54, no. 7-8, pp. 1634-1637, 2011.

[15] Spanish Statistics Institute (INE), http://www.ine.es/.

[16] Center for Sociological research (CIS), http://www.cis.es/cis/ opencms/EN/.

[17] The Organization for Economic Co-operation and Development (OECD), 2013, http://www.oecd.org/eco/outlook/spaineconomicforecastsummary.htm.

[18] Cross Asset Research. Sociéte Générale (SG), France, 2013, https://publication.sgresearch.com/en/3/0/172963/125179.html? $\mathrm{sid}=5 \mathrm{~b} 4256 \mathrm{~d} 8671034005116 \mathrm{a} 674000337 \mathrm{f} 9$.

[19] International Monetary Fund (IMF), 2013, http://www.imf.org/ external/pubs/ft/scr/2013/cr1354.pdf.

[20] C. Herrero, A. Soler, A. Villar, R. Aragón, and S. Sabater, La Pobreza en España y Sus Comunidades Autónomas, 2006-2011, Instituto Valenciano de Investigaciones Económicas, Valencia, Spain, 2012.

[21] B. Barreriro, "Justificaciones, responsabilidades y cumplimiento de promesas electorales," Revista Española de Ciencia Política, vol. 1, pp. 149-169, 1999 (Spanish).

[22] B. Barreiro and I. Sánchez-Cuenca, "Las consecuencias electorales de la corrupción," in Historia y Política, vol. 4, 2000.

[23] M. Cainzos and F. Jiménez, "El coste electoral de los escándalos: las elecciones generales de 1996," in Escándalos Politicos y Responsabilidad Pública en la España Contemporánea, UNED, Madrid, Spain, 2000.

[24] M. Duverger, F. Goguel, J. Cadart et al., "L'Influence des systèmes électoraux sur la vie politique," in Cahiers de la 
Fondation Nationale des Sciences Politiques, vol. 10, pp. 178-180, Cahiers Internationaux de Sociologie, 1951, (French).

[25] D. W. Rae, The Political Consequences of Electoral Laws, Yale University Press, New Haven, Conn, USA, 1967.

[26] W. H. Riker, "The two party system and Duverger's law," American Political Science, vol. 76, 1982.

[27] R. Taagepera and M. Shugart, Seats and Votes: The Effects and Determinants of Electoral Systems, Yale University Press, New Haven, Conn, USA, 1989.

[28] A. Nieto, El Desgobierno de España, Ariel, Barcelona, Spain, 2012, (Spanish). 


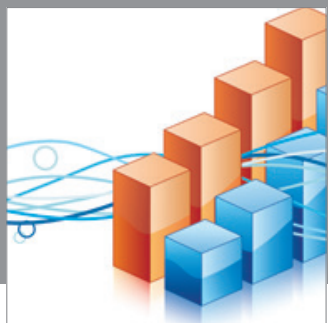

Advances in

Operations Research

mansans

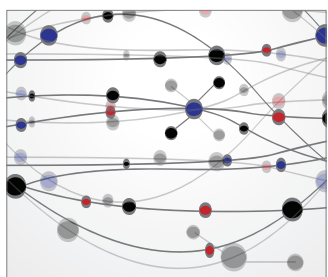

The Scientific World Journal

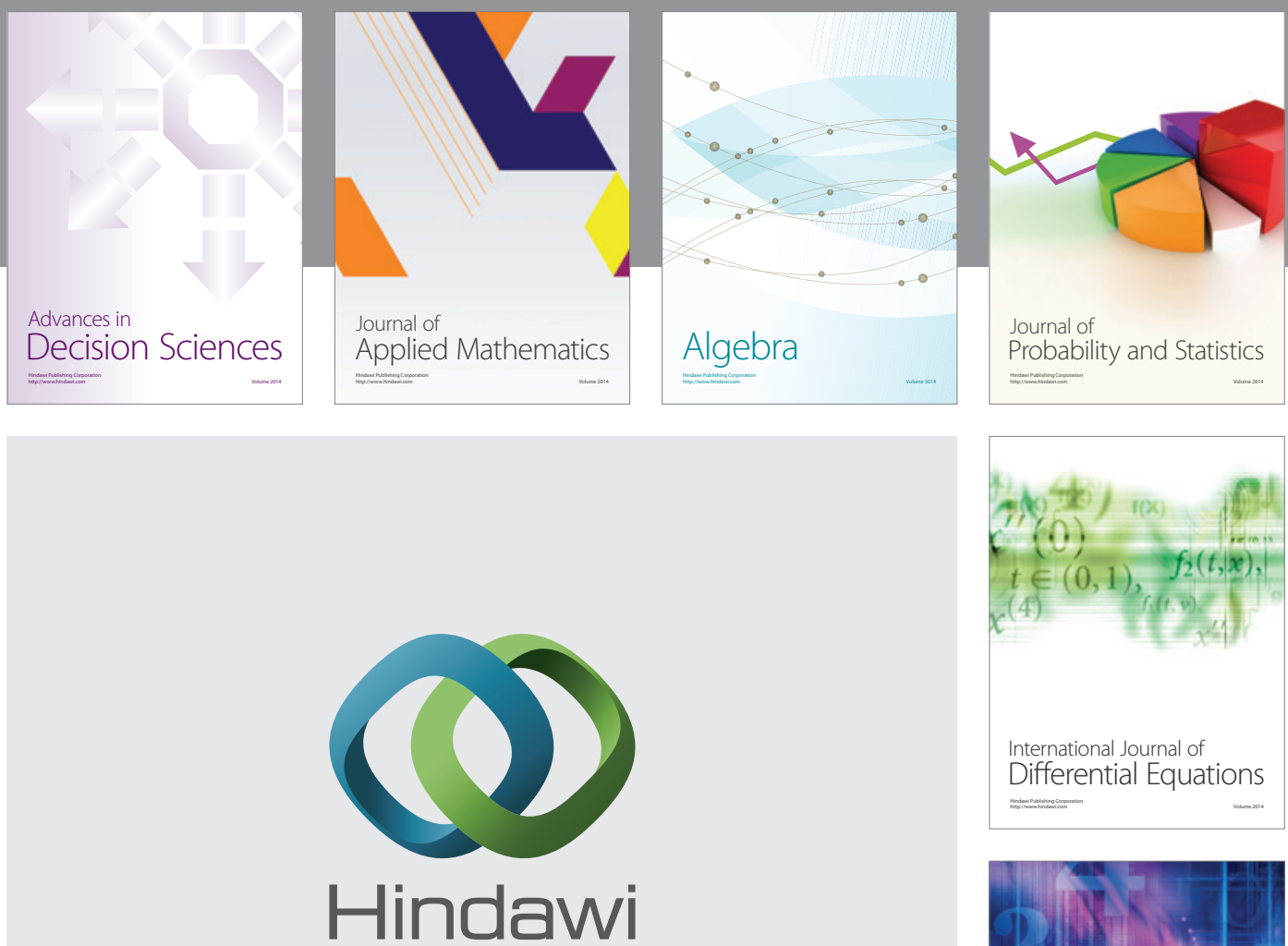

Submit your manuscripts at http://www.hindawi.com
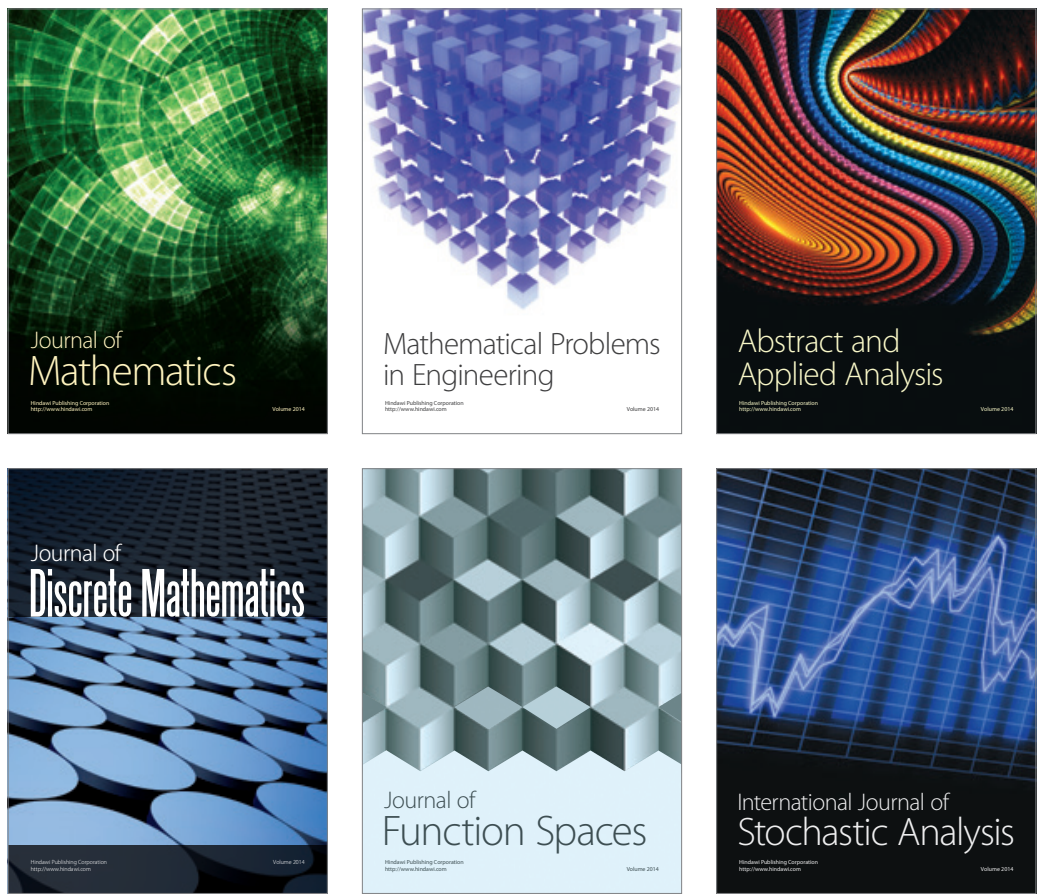

Journal of

Function Spaces

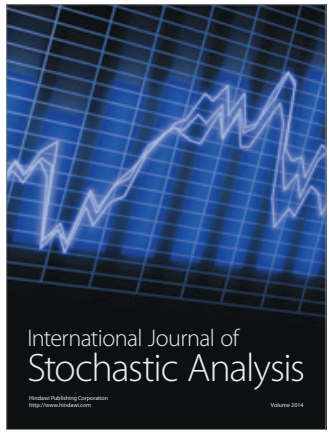

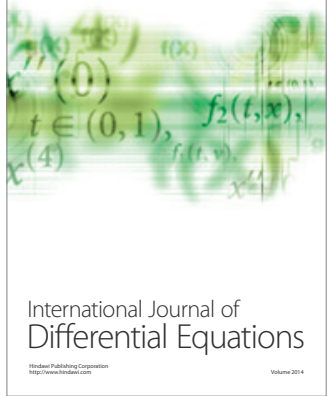
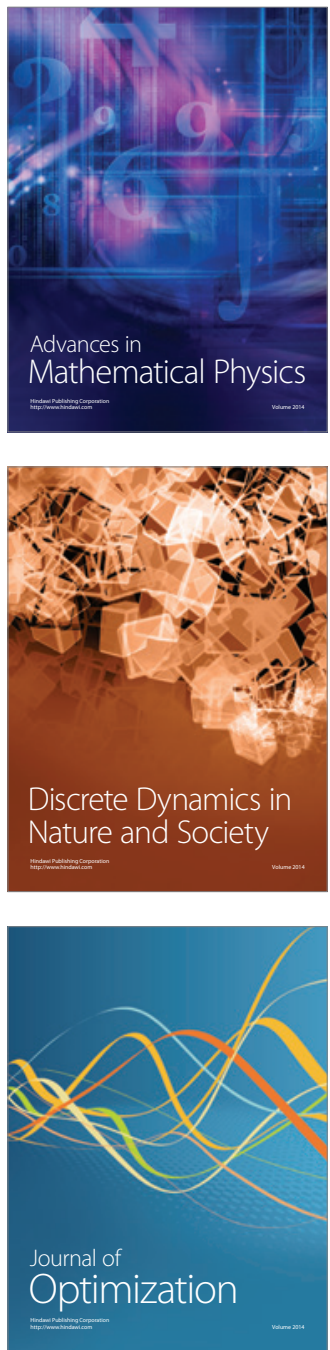